\title{
A HYBRID SIMULATION APPROACH IN DEVELOPING A RISK QUANTIFICATION MODEL FOR COAL PROCUREMENT IN POWER GENERATION
}

\author{
${ }^{1}$ Jafni Azhan Ibrahim, ${ }^{2}$ Hasimah Sapiri $\&{ }^{3}$ Razman Mat Tahar \\ ${ }^{1}$ School of Technology Management and Logistic, \\ Universiti Utara Malaysia, Malaysia \\ ${ }^{2}$ School of Quantitative Sciences, Universiti Utara Malaysia, Malaysia \\ ${ }^{3}$ Faculty of Technology Management, Universiti Malaysia Pahang, Malaysia \\ jafni@uum.edu.my; hsimah@uum.edu.my; razman779@ump.edu.my
}

\begin{abstract}
All energy systems provide some level of security to its consumers. However, the right or optimum level of security is very difficult to assess. In order to make a comparison between the cost of providing energy security and level of security, the quantified risks have to be in the common accounting platform of cost. Then, an optimum level of security and cost can be estimated using appropriate methods. Since no such attempts have been done to compare the risks and the cost in the same platform, i.e. monetary unit, it is unpractical to determine the optimum point between the risks and cost of providing security in any energy systems. The objective of this paper is to present a new hybrid simulation model in risk analysis which computes the total exposure of coal procurement in power generation through the summation of quantified supply shortage risk in monetary terms and the cost of coal procurement. The hybrid simulation model is made up of two main components: 1) Dynamic Risk Calculation Program (DR-P) which was developed in System Dynamics platform for capturing the effect of dynamics behavior of price toward coal procurement risk, and 2) Non-delivery Probability Table Program (NdPT-P) which was developed in Matlab platform for computing all possible shortage level and the probability of shortage in selected coal procurement portfolio. The result from this paper has shown that the risks of coal procurement were increased as the cost of coal procurement were decreased and vice versa. However, the summation of risk and cost which give the total exposure of coal procurement has provided more accurate information for selecting the best coal procurement portfolio option.
\end{abstract}


Keywords: Coal procurement, power generation, risk quantification, dynamics simulation, system dynamics.

\section{INTRODUCTION}

Energy has an important role for a virtuous cycle of human economic and social improvements. Sufficient supplies of energy will help raise standards of living, improve quality and quantity of human capital, enhance the business and natural environment, and increase the efficiency of government policies (OECD, 2007; IEA, 2010; Greenpeace \& EREC, 2010; UNDP, 2008; Birol, 2007). However, providing affordable, adequate, and reliable modern energy supplies to the vast majority of the world's population remains a major challenge and it has become the most critical energy issue for almost all developing countries. For these reasons, countries need to find ways to ensure a secure energy supply due to its important role as a production input and as a direct component in human wellbeing.

Achieving energy security can be understood as a defence against supply disruption and price instability. A safer, more secured, sustainable and affordable energy supply is crucial for a nation's economic and strategic interests. In its broadest meaning, "energy security" is the ability of a nation to muster the energy resources needed to ensure its welfare. In a narrower meaning, it refers to territorial energy autonomy (International Atomic Energy Agency, 2007). While many perfectly sound definitions of energy security are available, none is suitable to describe fully the effects of every element on energy security because it is a multifaceted notion (Jamasb \& Pollitt, 2008) and has a different meaning to different people at different moments in time (Alhajji, 2007).

In order to analyse any energy system, researchers must bear in mind that the system has its own inherent risk of insecurity (Greenleaf, Havmsen, Angelini, Green, Williams, Rix, Lefevre \& Biyth, 2009; Jamasb \& Pollitt, 2008; Kruyt, Van Vuren, De Vries \& Groenenberg, 2009). Basically, security of energy is in relation to risk. Many studies have been conducted to develop usable metrics and indicators that can be utilised to assess energy security policies and performance. Frequently, these metrics and indicators are divided into simple and complex indicators. Simple indicators are those that can be expressed in physical and monetary terms. They are more suitable for a rapid, snapshot appraisal of energy security. For example, resource estimates and reserves indicators provide resource and reserve estimates for fossil energy 
(USGS, 2000), reserve to production ratios (R/P) is commonly used to calculate the remaining amount of fossil fuels particularly oil and natural gas (Feygin \& Satkin, 2004), energy prices indicators can give an indication of the relationship between supply and demand(Markandya \& Pemberton, 2010) and the energy intensity indicator provides efficiency of energy resources being used. Meanwhile, complex indicators are those derived by diversity indices, such as the Herfindahl-Hirschman Index or Shannon-Wiener Index. They include the measurement of multiple variables and allow for depth of assessment. There are several methods for assessing the energy security using diversity of energy sources, fuel, and suppliers (Stirling, 1998; Jansen \& Seebuegts, 2010; APER, 2007). These methods are used in mitigating energy insecurity by providing resilience to systems exposed to uncertainty and ignorance in providing important means to hedge against supply risks and market power.

Although the above researches had shown vigorous work on analysing the multiple risks toward security of energy, they did not address any study on the energy security level itself. Furthermore, a $100 \%$ level of security is never intended for any systems for the reason that the costs would be excessive (Lieb-Doczy et al., 2008; NERA, 2002), so it would be wise if the optimal level of security could be determined. However, it is very difficult to determine the right or optimum level of security. In principle, the right or optimum level of security that a system provides is determined by the interaction between the cost of providing extra security and the value to consumers of the increase in security provided. Calculating this optimum level is difficult in the real world (NERA, 2002) because of the following issues: There is no explicit market for energy security and values have to be derived by indirect methods, energy security has some 'public good' characteristics, and different consumers will have different levels of willingness to pay.

In order to make a comparison between the cost of providing energy security and level of security, the quantified risks have to be in the common accounting platform of cost. Then, an optimum level of security and cost can be estimated using appropriate methods. Since no such attempts have been carried out to compare the risks and the cost in the same platform, i.e., monetary unit, it is unpractical to determine the optimum point between the risks and cost of providing security in any energy systems.

This paper aimed to introduce a new hybrid simulation model in risk assessment which compute the total exposure of coal procurement in power generation through the summation of quantified supply shortage risk in monetary terms 
and the cost of coal procurement. The hybrid simulation model is made up of two main components: 1) Non-delivery Probability Table component which was developed in MATLAB platform for calculating complex matrix structures of shortage level and the probability of shortage in selected coal procurement portfolio, and 2) Dynamic Risk Calculation component which was developed in System Dynamics platform for capturing the effect of dynamics behavior of price toward coal procurement risk and. This new hybrid method aims to extract useful characteristics from both methods by using risk assessment. This combination will give a dynamic cost function for risk of procurement shortage, in monetary terms, which can be compared directly against procurement cost - thus allowing for further steps in decision making process such as optimisation of procurement portfolio.

\section{OVERVIEW OF A COAL MARKET}

Coal is considered as one of the most important energy sources. Coal energy dominates about $40 \%$ out of the total power generated around the world (WCI, 2009; IEA, 2005). However, large coal deposits are located only in several specific geographical areas, namely Australia, South Africa, China, Indonesia and Colombia. These are the five main coal producers in the world, which accounted for an approximately $75 \%$ of the total thermal coal production (Warell, 2004). The geographical limitations become the motivation for international coal trading. Coals are traded worldwide using sea freight transportation. Many power producers rely on these imported resources in order for them to generate electrical power from coal energy (WCI, 2009).

The recent coal's price volatility crisis has triggered alarm and intensified vigilant efforts in coal procurement activities. The cost involved in coal power plants is largely dominated by fuel cost. Thus, electricity power producers are constantly facing challenges in maintaining fuel costs at its minimum level and ensuring profit gain from their operations. Simultaneously, coal supplies longevity is imperative for coal power producers since they have the commitment to provide electricity supply. Issues related to weather inclement, volatility in the coal market, freight market and logistic infrastructure are among the key coal producers (Loong, 2007) that could affect the continuity of coal supply.

For electricity power producers that relied on imported coal for main power generation, continuous supply of coal is very important in maintaining system security. Many strategies have been employed in order to ensure the 
sustainability of the supply. The most common strategy used is a diversification strategy (Suraini, 2009). According to this strategy, power producers try to diversify its suppliers, ports and even countries of origin. By this, they deal with long-term coal supply contracts with pegged annual prices in order to secure the coal supply. However, this strategy is deemed suitable to achieve price minimization for the coal supply only.

\section{COAL PROCUREMENT IN MALAYSIA POWER GENERATION}

In Malaysia, $90 \%$ of its coal for power generation is imported coal. This imported coal came from Australia (60\%), Indonesia (30\%), China and South Africa (5\% each). However, Suraini (2009) stated that Malaysia is currently stopping coal supplied from China. Malaysia coal power producers utilizes long-term contract and spot purchases in their transactions with the other three suppliers. Long term contracts are negotiated for the long run with annual price reviews.

About $80 \%$ of coal supply are negotiated and obtained through long-term contracts (Suraini, 2009) which were signed by international coal traders. In order to ensure supply security, the diversification concept (i.e. suppliers, ports, and country diversification) are employed by using multiple suppliers regardless of the prices offered. This paper presents a novel way in determining the procurement options in Malaysia, which is achievable by balancing between the procurement costs and risk involved in power generation system.

Malaysia Power Generators can manage their risk of coal supply by contracting the supply to various sources of suppliers, ports and countries. This paper assumes that the coal supply will be more secure if the sources are more diversified. This also means that a diverse source of coal supply contracts will lead to higher coal procurement costs since the best price offered will not be the main concern in the procurement options.

In the coal's contract arrangement, the power generators can manipulate the order quantity from each supplier. The quantity variation can be based on the capacity of the carrier vessels. In the international coal market, there are three types of vessels used for coal transportation. These vessels have different capacity, such as Capesize vessel (100,000 to 200,000 deadweight tonnages (dwt)), Panamax size vessel (60,000 to 75,000 dwt), and Handy size vessel (20,000 to 35,000 dwt). Thus, the quantity allocated for each supplier would be based on the capacity of these three types of vessel. 
In this arrangement, a coal procurement contract will be made up of two components. The first component consists of suppliers from different ports and countries and the second component consists of quantities based on the three types of vessels for every supplier. This practice allows for various possible combinations between suppliers and type of vessels which a company can choose from.

\section{METHODOLOGY}

Electricity power generators always have to deal with the reciprocal effect between procurement costs and its risk. The generators could try to minimize the level of risk by diversifying the coal supply resources and engaging with multiple suppliers and quantities. Else, they could try to minimize the procurement costs by dealing with only one supplier that offers the best price. The first strategy is not cost-effective and the latter will involve higher risk. Simultaneously, an electricity power generator has to pay procurement costs and deals with a finite level of risk. This scenario is captured in the Total Exposure equation model in Equation 1.

$$
T E=C o P+R o P
$$

where

TE : Total Exposure.

CoP : Cost of Procurement.

RoP : Risk of Procurement.

The objective of this research is to minimize Total Exposure (TE) faced by the Power Company. In Equation 1, Cost of Procurement $(\mathrm{CoP})$ is derived from the cost of coal supply paid to suppliers and is explained in Equation 2. It is the prices offered by each supplier multiplied with the quantities of coal allocated for each supplier. The second variable, Risk of Procurement (RoP), measured the risk at every level of interruption.

$$
C o p=L S_{i} \times P F_{i}
$$

where

CoP : Cost of Procurement.

$L S_{i} \quad$ : Load for Supplier $i$.

$P F_{i} \quad$ : Forecast Price of Supplier $i$.

The Total Exposure function takes into account all the above parameters in financial form. In Equation 1, increase cost of coal procurement will reduce risk of procurement and vice versa. This implies a unique combination of $C o P$ 
and $R o P$ will give a minimum $T E$ and the system is then deemed optimized as it balances the level of risk and the cost. Figure 1 show the flowchart to calculate RoP.

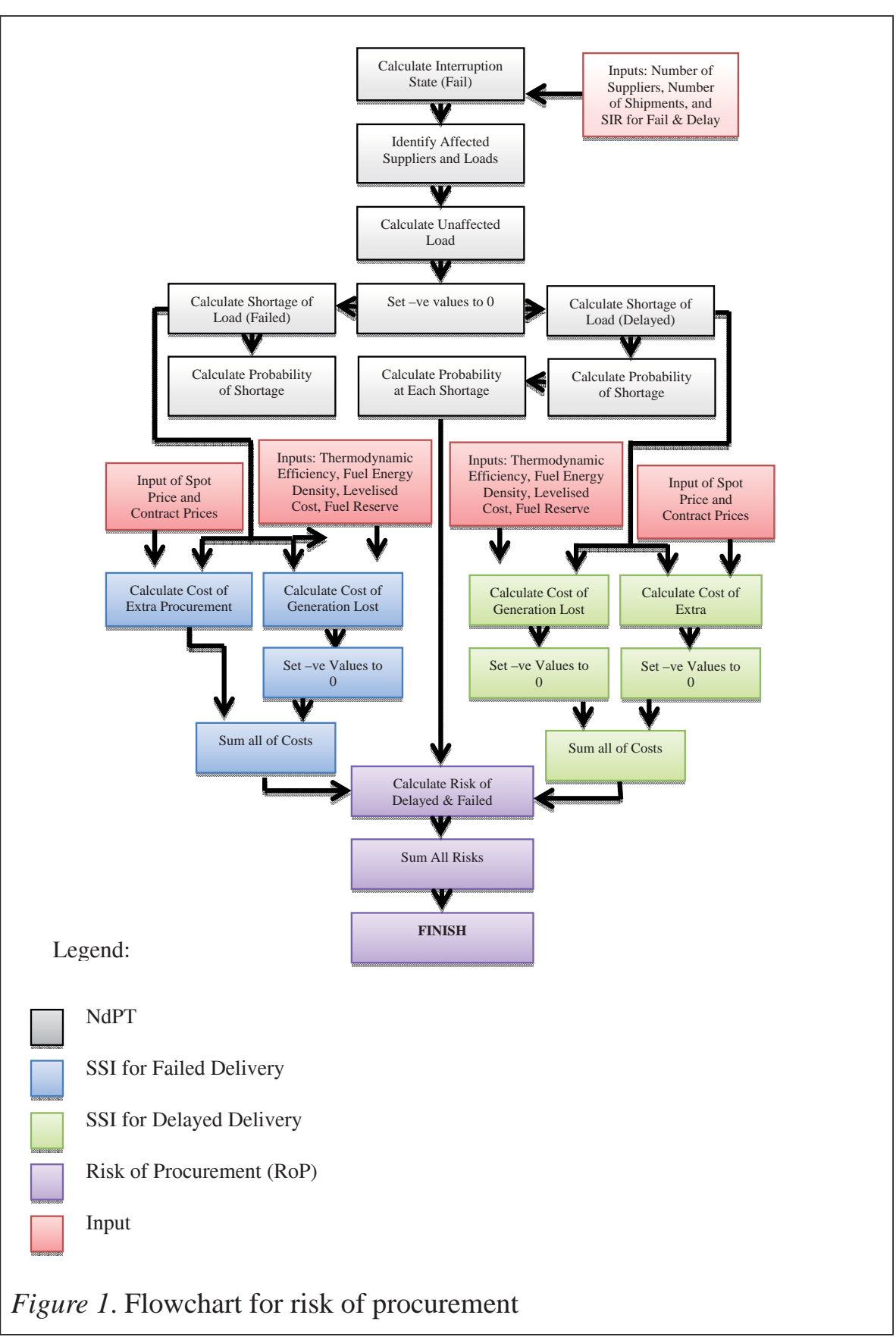


The following sub-section discusses the risk assessment program that has been synthesized and used in this paper. This program forms the core contribution of this paper by integrating the risk assessment techniques with coal procurement for power generation application using hybrid programming platform. In calculating Risk of Procurement the program is divided into three parts as shown in Figure 2. The first part of this program (NdPT-P) is written in MATLAB platform due to the development of complex matrix structure for calculating shortage level and the probability of shortage in selected coal procurement portfolio. Meanwhile, the second part, Dynamic Risk Program (DR-P), calculated others such as Supply Shortage Impact (SSI), Risk of Procurement (RoP), and Cost of Procurement (CoP) are written in System Dynamics platform in order to capture the dynamic behaviour of coal prices. Lastly, the third part, which is the data of the previous two parts, are communicated thought Microsoft Excel.

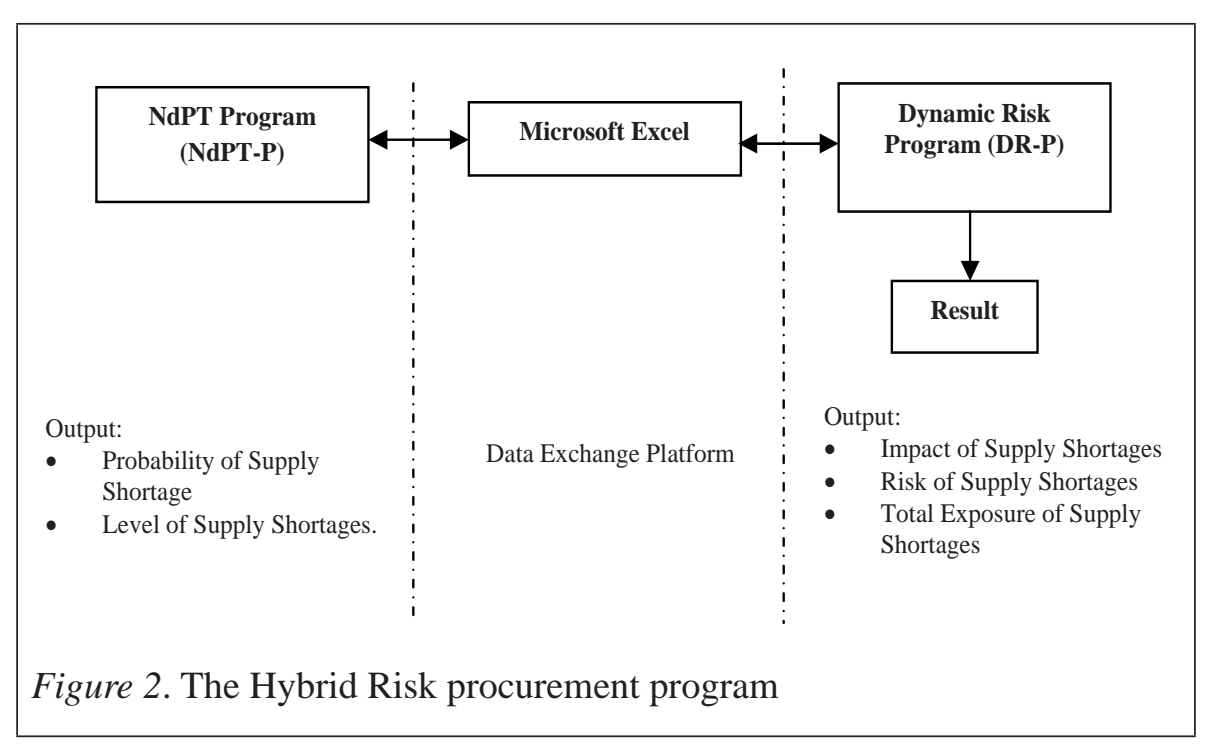

\section{Non-delivery Probability Table Program (NdPT-P)}

Non-delivery Probability Table program (NdPT-P) is a program that calculates the probability for all possible shortage levels. This program is developed in Matlab environment. Inputs for this program are taken from data such as number of shipments for every supplier. These inputs will be used to develop Non-delivery Probability Table (NdPT). The development of NdPT has been discussed thoroughly in Ibrahim, (2010a, 2010b). The output from this program, which is NdPT, will be sent to DR-P program to simulate the result. 


\section{Dynamic Risk Program (DR-P)}

The first component of Dynamic Risk Program (DR-P) is a program developed to calculate the Supply Shortage Impact (SSI), Risk of Procurement (RoP), and Cost of Procurement (CoP). In order to calculate SSI, cost of extra procurement and cost of generation loses are calculated for both possible supply shortages due to delayed and failed deliveries using Equation 3 to 6 .

$$
\begin{aligned}
D E P_{i} & =D S S_{i} \times\left(F S P-P F_{i}\right) \\
D G L_{i} & =\left(D S S_{i}-F R\right) \times F E D \times \frac{T E F}{1000} \times L C \\
F E P_{i} & =F S S_{i} \times\left(F S P-P F_{i}\right) \\
F G L_{i} & =\left(F S S_{i}-F R\right) \times F E D \times \frac{T E F}{1000} \times L C
\end{aligned}
$$

where

$\mathrm{DEP}_{i} \quad$ : Extra Procurement Cost due to Delayed Delivery from Supplier $i$.

$D G L_{i} \quad$ : Generation Lost due to Delayed Delivery from Supplier $i$.

$D_{S S} \quad$ : Supply Shortage due to Delayed Delivery from Supplier $i$.

FED : Fuel Energy Density.

$F E P_{i}$ : Extra Procurement Cost due to Failed Delivery from Supplier $i$.

$F G L_{i} \quad$ : Generation Lost due to Failed Delivery from Supplier $i$.

$F R \quad$ : Fuel Reserve.

$F_{i} \quad$ : Supply Shortage due to Failed Delivery from Supplier $i$.

FSP : Forecast Spot Price.

LC : Levelised Cost.

TEF : Thermodynamic Efficiency.

$P F_{i} \quad$ : Forecast Price of Supplier $i$.

Then, cost of extra procurement and cost of generation loses are added up together for SSI for both delayed and failed deliveries. Equations 7 and 8 explained the calculation for these SSI:

$$
\begin{aligned}
& D S S I_{i}=D E P_{i}+D G L_{i}, \\
& F I_{i}=D E P_{i}+D G L_{i},
\end{aligned}
$$

where

$D_{S S I} \quad$ : Supply Shortage Impact due to Delayed Delivery for Supplier $i$.

$D E P_{i}$ : Extra Procurement Cost due to Delayed Delivery from Supplier $i$.

$D G L_{i} \quad$ : Generation Lost due to Delayed Delivery from Supplier $i$.

FSSI $_{i}$ : Supply Shortage Impact due to Failed Delivery for Supplier $i$. 
$F_{i} \quad$ : Extra Procurement Cost due to Failed Delivery from Supplier $i$.

$F G L_{i} \quad$ : Generation Lost due to Failed Delivery from Supplier $i$.

Next, risk of procurement for supplier $i, R_{0} P_{i}$ is calculated by multiplying supply shortage impact for supplier $i, S S I_{i}$ with probability of delayed and failed delivery. Equation 9 explained the calculation for these SSI:

$$
R o P_{i}=\left(D S S I_{i} \times D P R_{i}\right)+\left(F S S I_{i} \times F P R_{i}\right),
$$

where

$R_{i} P_{i} \quad$ : Risk of Procurement for Supplier $i$.

$D S S I_{i}$ : Supply Shortage Impact due to Delayed Delivery for Supplier $i$.

$D P R_{i} \quad$ : Probability of Delayed Delivery for Supplier $i$.

FSSI $_{i}$ : Supply Shortage Impact due to Failed Delivery for Supplier $i$.

$F P R_{i} \quad$ : Probability of Failed Delivery for Supplier $i$.

Finally, risk of procurement for every supplier are added together to give the total risk of procurement $(R o P)$ as explained in Equation 10:

$$
R o P=\sum_{i=1}^{n} R o P_{i},
$$

where

RoP : Total Risk of Procurement.

$R_{i} P_{i} \quad$ : Risk of Procurement for Supplier $i$.

$n \quad$ : Total number of supplier.

The dynamics values of forecast price for every supplier $\left(\mathrm{PF}_{i}\right)$ and forecast price for spot market (FSP) are captured in the program in running these equations in System Dynamics platform. These values are dependent on the time of delayed and failed shipments. Therefore, these values of SSI are considered to be time depending. Meanwhile, the values of supplier's supply shortage due to delayed (DSS ${ }_{i}$ ) and failed delivery $\left(\mathrm{FSS}_{i}\right)$ in the equations are extracted from NdPT-R.

\section{SIMULATION DATA}

In order to illustrate the optimization program, the following example is used based on the current practices of Malaysia coal power producer. The coal suppliers' data and coal buyers' data are tabulated below. In order to has more 
accurate results, 6 years data are gathered (Hashim, Tahar, and Abu Bakar, 2003). Altogether, there are three different coal-producing countries and five coal suppliers were selected and included in this research. It is assumed that the Freight on Board (FOB) prices identified in this paper are for coal capacity of $6,000 \mathrm{kcal} / \mathrm{kg}$. Table 1 summarizes FOB prices for all countries from year 2004 to year 2009 (IEA, 2010 and 2007).

Table 1

Freight on Board Prices for All Countries

\begin{tabular}{cccc}
\hline Year & $\begin{array}{c}\text { Australia } \\
\text { (USD/mt) }\end{array}$ & $\begin{array}{c}\text { Indonesia } \\
\text { (USD/mt) }\end{array}$ & $\begin{array}{c}\text { South Africa } \\
\text { (USD/mt) }\end{array}$ \\
\hline 2004 & 37.65 & 38.00 & 32.94 \\
2005 & 48.86 & 44.50 & 46.21 \\
2006 & 47.05 & 47.25 & 45.78 \\
2007 & 51.11 & 60.91 & 51.06 \\
2008 & 92.23 & 115.48 & 88.19 \\
2009 & 80.03 & 55.29 & 60.99 \\
\hline
\end{tabular}

Table 2 depicts the percentages of price increments according to production countries.

Table 2

Percentage of Increment for Every Country

\begin{tabular}{|c|c|c|c|}
\hline Year Country & Australia (\%) & Indonesia (\%) & South Africa (\%) \\
\hline 2004 to 2005 & 29.77 & 17.10 & 40.28 \\
\hline 2005 to 2006 & -3.70 & 6.17 & -0.93 \\
\hline 2006 to 2007 & 8.62 & 28.91 & 11.53 \\
\hline 2007 to 2008 & 80.45 & 89.59 & 72.71 \\
\hline 2008 to 2009 & -13.22 & -52.12 & -30.84 \\
\hline
\end{tabular}

Based on these percentages of increment, FOB prices are forecasted. It is assumed that the forecasted prices are following the existing incremental trends in Table 2 and are rotating along the forecasted years. Table 3 shows the forecasted prices for all three countries. 
Table 3

Forecast Price for All Countries

\begin{tabular}{|c|c|c|c|}
\hline Year Country & $\begin{array}{l}\text { Australia } \\
\text { (USD/mt) }\end{array}$ & $\begin{array}{l}\text { Indonesia } \\
\text { (USD/mt) }\end{array}$ & $\begin{array}{c}\text { South Africa (USD/ } \\
\mathrm{mt})\end{array}$ \\
\hline 2010 & 103.86 & 64.75 & 85.56 \\
\hline 2011 & 100.01 & 68.75 & 84.76 \\
\hline 2012 & 108.64 & 88.62 & 94.54 \\
\hline 2013 & 196.05 & 168.02 & 163.29 \\
\hline 2014 & 170.11 & 80.45 & 112.92 \\
\hline 2015 & 220.76 & 94.21 & 158.42 \\
\hline 2016 & 212.59 & 100.03 & 156.94 \\
\hline 2017 & 230.93 & 128.95 & 175.05 \\
\hline 2018 & 416.72 & 244.47 & 302.34 \\
\hline 2019 & 361.60 & 117.05 & 209.09 \\
\hline 2020 & 469.26 & 137.07 & 293.32 \\
\hline
\end{tabular}

Due to the distance between the suppliers ports and the power plants, cost of insurance and freight (CIF) would differ accordingly. It is assumed that CIF from South Africa is the highest, followed by Australia and Indonesia. Subsequently, Table 4 illustrates the CIF prices for all suppliers. These prices are identified based on the forecasted prices and percentages of CIF accordingly.

Table 4

Cost of Insurance and Freight Prices for All Suppliers

\begin{tabular}{cccccc}
\hline Year & Supplier 1 & Supplier 2 & Supplier 3 & Supplier 4 & Supplier 5 \\
\hline 2010 & 125.63 & 123.63 & 72.22 & 70.22 & 91.29 \\
2011 & 121.01 & 119.01 & 76.62 & 74.62 & 97.01 \\
2012 & 131.37 & 129.37 & 98.49 & 96.49 & 125.43 \\
2013 & 236.26 & 234.26 & 185.83 & 183.83 & 238.97 \\
2014 & 205.14 & 203.14 & 89.49 & 87.49 & 113.74 \\
2015 & 265.92 & 263.92 & 104.63 & 102.63 & 133.42 \\
2016 & 256.10 & 254.10 & 111.03 & 109.03 & 141.74 \\
2017 & 278.12 & 276.12 & 142.84 & 140.84 & 183.10 \\
2018 & 501.07 & 499.07 & 269.92 & 267.92 & 348.30 \\
2019 & 434.92 & 432.92 & 129.76 & 127.76 & 166.08 \\
2020 & 564.12 & 562.12 & 151.78 & 149.78 & 194.71 \\
\hline
\end{tabular}


In cases of coal delivery interruptions, the company has to purchase the interrupted supply at the spot market at a higher price. Table 5 estimated the FOB spot prices in the Pacific market by IEA (2010).

Table 5

Estimated FOB Spot Prices in Pacific Market

\begin{tabular}{cc}
\hline Year & Spot Price (USD/mt) \\
\hline 2004 & 72.12 \\
2005 & 85.46 \\
2006 & 63.32 \\
2007 & 108.35 \\
2008 & 193.23 \\
2009 & 140.46 \\
\hline
\end{tabular}

Surani (2009) stated that the coal supply from Indonesia has the highest probability of delays or failures. This is associated with weather inclement and political intervention factors. Concurrently, coal supply interruptions from Australia are mostly due to port congestions, especially at Gladstone port. Surani also mentioned that the possibility of delivery delays surpassed the possibility of delivery failures. Another coal buyer data is used to simulate the program. It is assumed that the annual demand for coal supply amounting to $750,000 \mathrm{mt}$ are contracted among several suppliers to generate electricity for all coal power plants.

\section{SIMULATION AND RESULTS}

Data from an electricity producer company that needs 750,000 metric tonne (mt) of coal per year to generate electricity is used in this analysis. This is to illustrate the various interruption risks that can be experienced by a plant. A long-term coal contract will be awarded to selected suppliers from 2010 to 2020. Suppliers from different locations are contracted to supply coal for utility providers. According to Surani (2009), this is a practical application in procurement strategies for all utility providers. Five different suppliers at four different major ports are included in order to illustrate the supplier selection process. The four major ports considered are Kalimantan in Indonesia, Newcastle and Gladstone in Australia and Richards Bay in South Africa. At random, there are four different procurement options (Table 6(a) -Table 6 (d)), which are intended to increase the number of shipments. 
Table 6 (a)

Procurement Option with 5 Shipments

\begin{tabular}{cccc}
\hline Supplier & \multicolumn{3}{c}{ Shipments } \\
\cline { 2 - 4 } & Capesize & Panamax & Handy \\
\cline { 2 - 4 } 2 & 0 & 1 & 0 \\
3 & 0 & 1 & 0 \\
4 & 1 & 0 & 0 \\
5 & 1 & 0 & 0 \\
\hline
\end{tabular}

Table 6 (b)

Procurement Option with 10 Shipments

\begin{tabular}{cccc}
\hline Supplier & \multicolumn{3}{c}{ Shipments } \\
\cline { 2 - 4 } & Capesize & Panamax & Handy \\
\hline 1 & 0 & 2 & 0 \\
2 & 0 & 2 & 0 \\
3 & 0 & 2 & 0 \\
4 & 0 & 2 & 0 \\
5 & 0 & 2 & 0 \\
\hline
\end{tabular}

Table 6 (c)

Procurement Option with 11 Shipments

\begin{tabular}{cccc}
\hline Supplier & \multicolumn{3}{c}{ Shipments } \\
\cline { 2 - 4 } & Capesize & Panamax & Handy \\
\cline { 2 - 4 } 1 & 0 & 1 & 1 \\
2 & 0 & 1 & 1 \\
3 & 0 & 1 & 1 \\
4 & 1 & 1 & 1 \\
5 & 0 & 1 & 1 \\
\hline
\end{tabular}

Table 6(d)

Procurement Option with 12 Shipments

\begin{tabular}{cccc}
\hline Supplier & \multicolumn{3}{c}{ Shipments } \\
\cline { 2 - 4 } & Capesize & Panamax & Handy \\
\cline { 2 - 4 } 1 & 0 & 0 & 2 \\
2 & 0 & 0 & 2 \\
3 & 1 & 0 & 2 \\
4 & 1 & 0 & 2 \\
5 & 0 & 0 & 2 \\
\hline
\end{tabular}


Figure 3 demonstrates the procurement cost for every option in the simulation. Generally, this figure shows the cost increments from year to year. However, it is projected that there will be a radical price increment in the year 2013 and 2018. The radical changes are predicted based on historical data obtained in 2008. It could also be concluded that the option with 12 shipments has the lowest procurement cost all along the years. At the same time, with the exception of year 2013, the option with 5 shipments has the lowest procurement cost of USD 139,749,396.87. Contradictorily, option with 10 shipments shows the highest values in annual procurement cost. However, the option with 5 shipments recorded the highest price in USD 205,337,474.61.

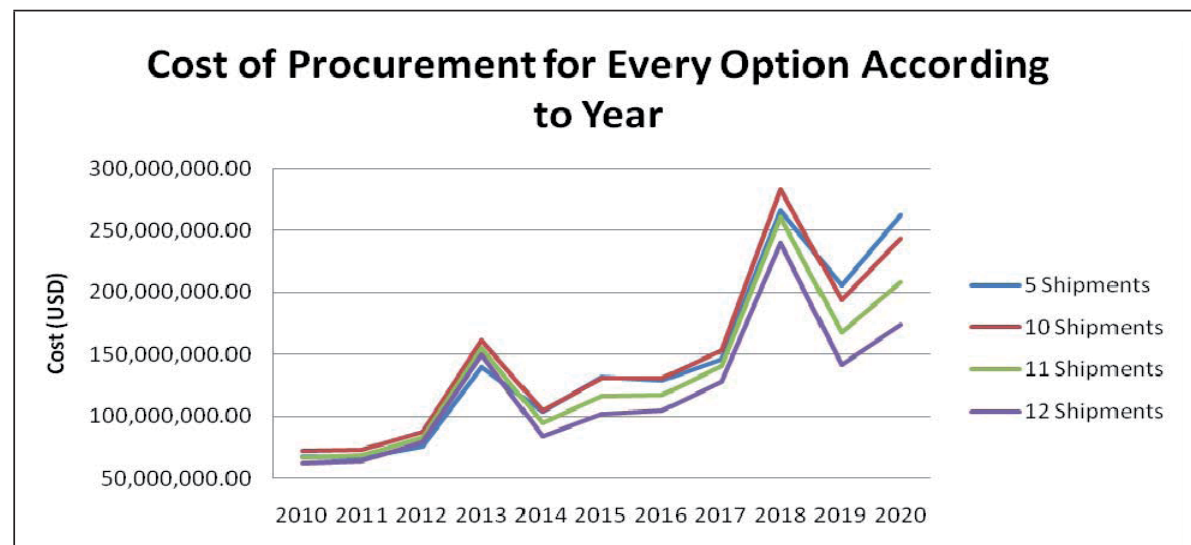

Figure 3. Cost of procurement for every option according to year

Figure 4 illustrates the annual procurement risk for every option. There is an upward annual trend in procurement risk. However, the trend fluctuates dramatically in the year 2016 and 2017. It is expected that risk will decrease in 2016 and then will rise sharply in 2017. It could also be concluded that 10 shipments' option has the lowest procurement risk over the years. This is due to an even distribution of the number of shipments among all suppliers. Meanwhile, option with 12 shipments shows the highest value of procurement risk over the years. This could be related to the significant dependency on suppliers with higher probability of supply interruption rates (SIR).

Figure 5 presents the total exposure for every option according to year. This figure generally followed the pattern of procurement cost with two extremities in the years 2013 and 2018. Option with 12 shipments has the highest values in total exposure for all the forecasted year. However, the lowest values of total exposure is identified to be a combination of a few other options, where an option with 5 shipments superseded the others in most of the year. 


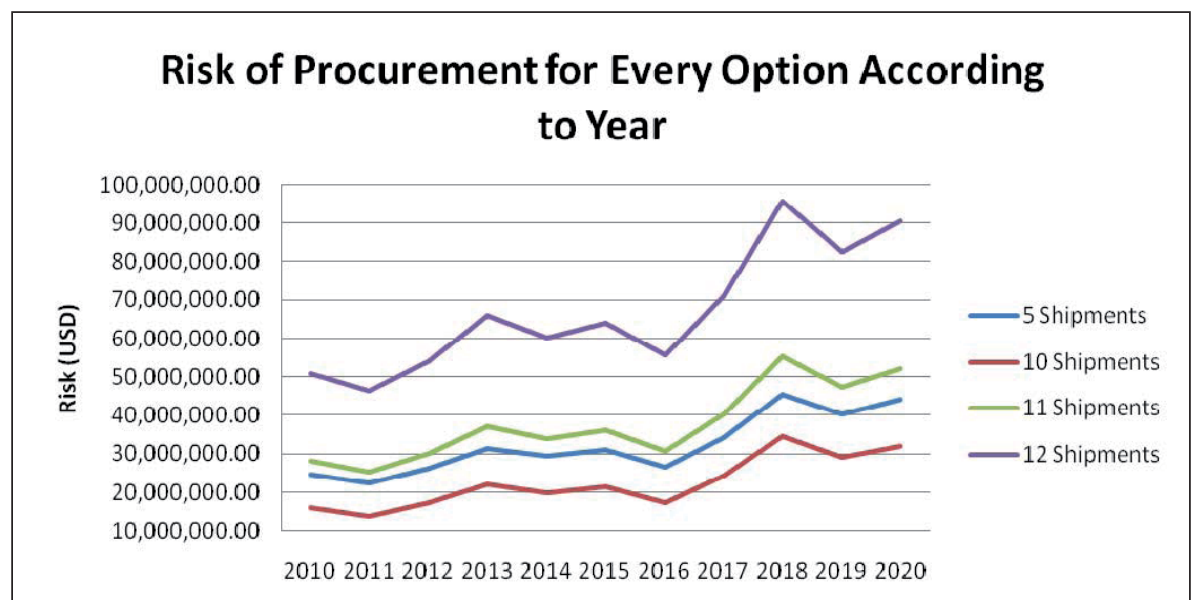

Figure 4. Risk of procurement for every option according to year

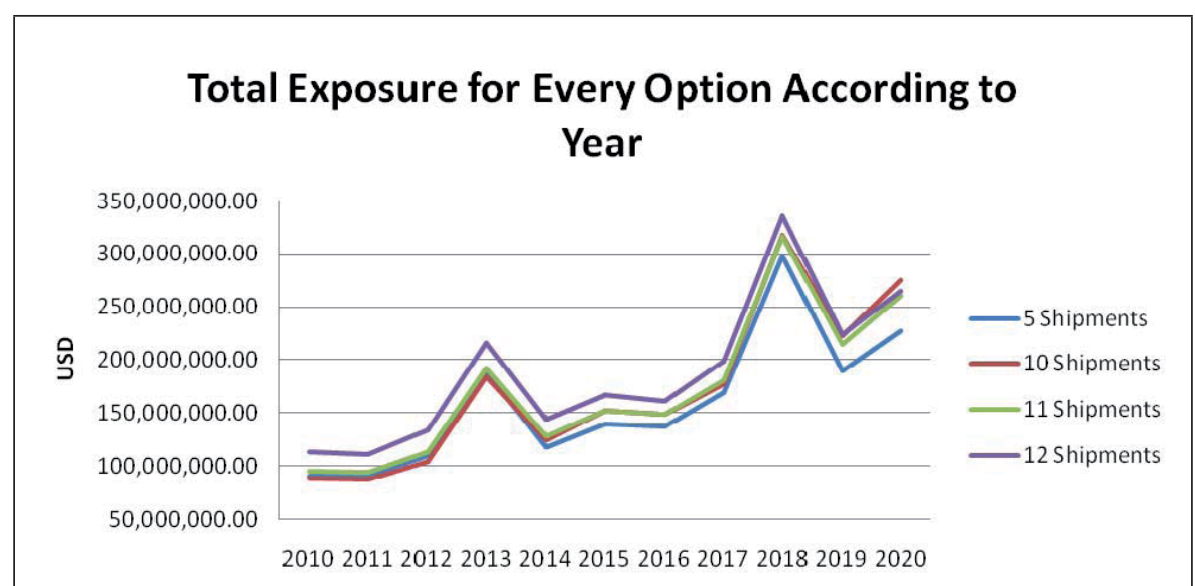

Figure 5. Total exposure for every option according to year

\section{CONCLUSION}

This paper illustrates the development of a hybrid model that can be used in quantifying the risk in coal electricity generation system. The proposed method can also be a tool to assist in the coal's contract price negotiation process. It provides information regarding the significant impact of coal price on power utility company's risk. Incorporating the coal price into the equations above will provide valuable information on the best price for coal contracting which would benefit both parties. 


\section{REFERENCES}

Alhajji, A. F. (2007). What is energy security? Definition and concepts. Middle East Economic Survey.

Asia Pacific Energy Research Center. (2007). A quest for energy security in the $21^{\text {st }}$ century: Resources and constraints. APERC, Tokyo, Japan. Retrieved from http://www.ieej.or.jp/aperc.

Birol, F. (2007). Energy economics: A place for energy poverty in the agenda? The Energy Journal, 8(3), 1-6.

Feygin, M., \& Satkin, R. (2004). The oil reserve-to-production ratio and its proper interpretation. Natural Resource Research, 13, 57-60.

Greenleaf, J., Harmsen, R., Angelini, T., Green, D., Williams, A., Rix, O., Lefevre, N., \& Blyth, W. (2009). Analysis of impacts of climate change policies on energy security. Final Report. European Commission DG Environment.

Greenpeace \& EREC (European Renewable Energy Council). (2010). Energy [R] evolution: A sustainable world energy outlook. Greenpeace International and EREC.

Hashim, S., Mat Tahar, R., \& Engku Abu Bakar (2003). Simulation study for improving patient treatment services. Journal of Information and Communication Technology, 2, 87-104.

Ibrahim, J. A., Hashim, A., Majid, M., \& Mat Tahar, R. (2010a). Risk quantification in coal procurement for power generation: the development of supply shortage impact matrix. Proceeding of 2 nd International Conference on Computer Intelligence, Modelling, and Simulation. IEEE Computer Society, 401-406.

Ibrahim, J. A., Hashim, A., Majid, M., \& Mat Tahar, R. (2010b). The development of novel approach for risk quantification in coal procurement. Proceeding of 4th International Power Engineering and Optimization Conference. IEEE, 255-260.

International Atomic Energy Agency. (2007). Analysis of energy supply options and security of energy supply in the Baltic states, Vienna, Austria. Retrieved from http://www-pub.iaea.org/MTCD/Publications/ PDF/te_1541_web.pdf.

International Energy Agency, IEA. (2005). Lessons from liberalized electricity markets, IEA/OECD, Paris. Retrieved from http://www.iea.org/textbase/ nppdf/free/2005/lessons2005.pdf.

International Energy Agency, IEA. (2007). Energy security and climate policy-assessing interactions, Paris, IEA/OECD. Retrieved from http://www.iea.org/textbase/nppdf/free/2007/energy_security_climate_ policy.pdf. 
International Energy Agency, IEA. (2010). Coal information 2010 with 2009 data, Paris, IEA/OECD. Retrieved from http://wds.iea.org/wds/pdf/ documentation_Coal_prelim2010.pdf.

Jamasb, T., \& Pollitt, M. (2008). Security of supply and regulation of energy network. Energy Policy, 38, 4584 - 4589.

Jansen, J. C., \& Seebregts, A. J. (2010). Long-term energy services security: What is it and how can it be measured and valued? Energy Policy, 38, 1654-1664.

Kruyt, B., Van Vuuren, D. P., De Vries, H. J. M., \& Groenenberg, H. (2009). Indicator for energy security. Energy Policy, 38, 2166 - 2181.

Lieb-Doczy, E., Borner, A. R., \& MacKerron, G. (2008). Who secures the security of supply? European perspectives on security, competition, and liability. The Electricity Journal, 16, 10-19.

Loong, H. C. (2007). Coal demand outlook in Malaysia. APEC Clean Fossil Energy Seminar, China.

Markandya, A., \& Pemberton, M. (2010). Energy security, energy modelling and uncertainty. Energy Policy, 38, 1609-1613.

NERA. (2002). Security in gas and electricity market. UK Department of Trade and Industry Report.

Stirling, A. (1998). On the economics and analysis of diversity. Paper No. 28, Science Policy Research Unit (SPRU), University of Sussex. Retrieved from https://www.sussex.ac.uk.

Surani, N. A. ( personal communication, October 2009). Coal Procurement Manager, TNB Fuel Sdn. Bhd., Kuala Lumpur, Malaysia.

United Nations Development Programme (UNDP). (2008). Expanding access to modern energy services: replicating, scaling up and mainstreaming at the local level - lessons from community-based energy initiatives. New York. Retrieved from http://94.126.173.140/downloads/cc_factsheet. pdf.

U.S. Geological Survey (2000). World petroleum assessment 2000.

Warrel, L. (2004). Defining geographic coal market using price data and shipments data. Energy Policy, 33, 2210- 2230.

World Coal Institute, (2009). Coal: secure energy. Retrieved from http//:worldcoal.org. 